\title{
Anger, Depression and Locus of Control among Heavy Smokers, Cannabis Users and Heroin Addicts
}

\author{
Ather Mujtaba $^{1 *}$, Farah Malik ${ }^{1}$, Rabia Iftikhar ${ }^{1}$
}

\section{ABSTRACT}

The purpose of the study was to explore relationship and difference in anger, depression, and locus of control among Heavy smokers, cannabis users and heroin addicts along with identifying the determinants of depression. Purposive sampling technique was employed to draw sample. Sample was consisted of 150 male adults between ages ranging from 18 to 36 years who were divided equally in three groups. Participants were recruited from five cities of Punjab. Three assessment tools were used in data collection, Trait Anger Expression Scale (Rashid \& Siddiqui, 2005), Siddiqui Shah Depression Scale (Siddiqui \& Shah, 1992) and Drug Related Locus of Control (Hall, 2001). Result reveled that Expressive and state anger significantly correlated with depression among three groups. Anger, depression and DRLOC only associated in smokers. MANOVA showed that heroin addicts had very high level of expressive anger and depression than heavy smokers and cannabis users, while significant high anger in as compare to heavy smokers. Expressive anger, quantity of drug intake, DRLOC and quantity of smoking were predicted depression in whole sample. Expressive anger identified as main predictor of depression in smokers, cannabis users and heroin addicts.

Keywords: Anger, Depression, Locus of Control, Smokers, Cannabis Users, Heroin Addicts.

Anger is usually caused by the frustration of attempts to attain a goal, or by hostile or disturbing actions such as insults, injuries, or threats that do not come from a feared source (Gale Encyclopedia of Psychology, 2001). Anger can be state or trait. State anger is situational anger which is provoked in response to intense situation. Trait anger is personality tendency to burst out easily on minor things. Tafrate, Kassinove, and Dundin(2002) concluded that anger reaction of people with trait anger is more intense, frequent and enduring. It may have consequences of prompted negative cognition, physical aggression, negative response and drug use. While internalized anger and less control on expression is linked with depression, anxiety and hostility symptoms (Bridewell \& Chang, 1998).

The relationship between stress and anger is high in smokers than non-smokers that further leads to more smoking (Nazar, 2008; Malik, 2009). Many studies have been found cigarette smoker

\footnotetext{
${ }^{1}$ Clinical Psychology Unit, Department of Psychology, GC University Lahore, Pakistan *Corresponding Author

(C) 2015 I A Mujtaba, F Malik, R Iftikhar; licensee IJIP. This is an Open Access Research distributed under the terms of the Creative Commons Attribution License (http://creativecommons.org/licenses/by/2.0), which permits unrestricted use, distribution, and reproduction in any Medium, provided the original work is properly cited.
} 
experience more anger than non-smokers (Al' Absi, Carr, \& Bongard, 2007; Nazar, 2008; Malik, 2009). Killen, Fortmann, Telch, \& Newman (1988) proposed that heavy smokers are more likely to have nicotine dependence. Burgermeister (2009) explored that adults with nicotine dependence were experienced more major depression episode than nondependent. That indicates heavy smokers are vulnerable for depression or other psychiatric problems. As findings showed that up to 60\% heavy smokers had history of mental illness (Hughes, Hatsukami, Mitchell, \& Dahlgen, 1986). Anger presentation is more intense in drug users. They have tendency to arouse easily and have less control on expression of anger (Carmelo, De Moja, \& Spielberger, 1997).

The similar relationship was evidenced in cannabis users, people who try to overcome their depression with cannabis, may increase chances of further progression in depression. Arendt et al. (2007) indicated that use of cannabis is associated with life time depression. While under the influence of cannabis they experience more depression, sadness, anxiety and paranoia. Studies also found that continuous cannabis use increase chances of depression. Degenhardt, Hall, and Lynskey (2001) found positive association between depression and heavy use of cannabis. Though heavy cannabis use and depression are widely correlated in different researches yet this relation is not clearly associated with anger.

Heroin addicts have high anger, hostility and depression level in hospitalized and nonhospitalized heroin addicts (Sordo et al., 2012; Wield et el. 2005; Rao, Broom, \& Simpson, 2004; Ahmad \& Mufti, 1998). USNSODU (2006) heroin addicts are at risk for developing depression. Heroin addicts have more anxiety, depression, preoccupation with health, health illness self-blame, health monitoring, and negative thinking about health. These all factors were directly associated with hopelessness, dysthymic and irritable temperament (Iliceto et al. 2011).Some other studies also illustrated personality characteristics of heroin addicts and more external locus of control among drug abusers (Niazi, Pervaiz, Minhas, and Najam, 2004).

Locus of control is described as individual's perceived belief concerning the determinants of rewards and punishments, i.e. the ability to control events (Rotter, 1966). As cited by Farbstein, 2011, McClun and Merrel (1998) people who have believed on internal locus of control always perceive their action and behavior effecting outcome of any event and use practical approach and less avoidant coping strategies than individuals with external locus of control. People with external locus of control believe on outside forces as chance, fate, and luck determine outcome of event (Gizir \& Aydin, 2009; McClun \& Merrel, 1998; Tella, Tella, \& Adika, 2008). Individuals with external locus of control were careless, easily influenced by external forces, less self-confident, and displaying unsteady performances (Rotter, 1975). Bergen and Coporaso (1999) explained that teenage smoker has external health locus of control as compared to nonsmoking teens. Later this sense of external locus of control involved them in more habitual smoking. Cannabis user and heroin addicts have literally high external locus of control. De Moja (1997) narcotics abusers who have high score on external locus of control are prone to anger, anxiety, stress and depression. They satisfy themselves with drugs, as it gives them way of 
escape from reality or loss of control on life event. Benassi, Sweeney, Dufour, and Charles, (1988), they found significant positive relationship between external locus of control and depression (as cited by Abdolmanafi, Besharat, Farahani, \& Khodaii, 2007). Locus of control relation with depression has been examined in multiple researches and found, that people with depression have more external locus of control, As concluded, higher levels of depression are associated with higher levels of external LOC (e.g., Benson \& Deeter, 1992; Hooke \& Page, 2002; Kennedy, Lynch, \& Schwab, 1998; Macleod \& Macleod, 1998; Robinson \& Kelley, 1998).In the light of above mentioned researches, the present study examined the relationship and differences in anger depression and locus of control among heavy smokers, cannabis users and heroin addicts. Secondly, identify the role of anger and locus of control in depression among smokers, cannabis users and heroin addicts.

\section{HYPOTHESES}

- Anger, depression and locus of control may have relationship in smokers, cannabis users and heroin addicts.

- Anger, depression and Drug related locus of control would be different in heroin addicts than smokers and cannabis users.

- Anger and Drug related locus of control would predict depression among smokers, cannabis users and heroin addicts.

- Demographic variables as age, income, occupation, marital status, family systems and number of treatment may have effects on anger, depression and locus of control among smokers, cannabis users and heroin addicts

\section{METHOD}

\section{Participants}

Participants were divided in three equal groups, cigarette smokers, Cannabis users, and Heroin addicts. Sample size was consisted of 150 male adult participants, 50 participants for each group between age ranges of 18 - 36 years $(M=26.95, S D=4.76)$ and for Smokers age was $(M=27.88$, $S D=4.46)$, Cannabis users age was $(M=26.26, S D=4.8)$, and Heroin Addicts age was $(M=$ 26.26, $S D=4.8$ ). Purposive sampling technique was used to draw sample, criteria were set according to DSM-IV-TR diagnostic criteria of substance dependent. The main data were collected from five Cities of Punjab (Lahore, Gujranawala, Gujrat, Kharian and Wazirabad).

\section{Inclusion criteria}

- Only male adult participants were selected between age ranges of 18-36 years.

- Cigarette smoker must smoke 20 cigarettes on daily basis for at least last one year. Occasional use of alcohol was ignored that had been taken before two months at time of data collection.

- Cannabis user must use cannabis daily for at least last one year. Occasional use of alcohol was ignored that had been taken two month before at time of data collection.

- Heroin addict who used heroin for the last one year and did not use any other drug with heroin like cannabis, alcohol, opium and synthetics. 


\section{Measures}

Siddiqui Shah Depression Scale (Siddiqui \& Shah, 1992). It has 36 items with four point rating scale (never $=0$, rarely $=1$, often $=2$ and always $=3$ ). There is no reverse scoring of any item. It has minimum score zero and maximum 108. It measures severity level of depression as between 21- 36 score indicated "mild depression”, 37- 49 "moderate depression" and Above 50 "severe depression".

The scale had good construct and concurrent validity and reliability. The author has given split half reliability for clinical population $r=.79$ and for non-clinical group $r=.81$. While, alpha coefficient calculated $\alpha=.92$ for clinical population and $\alpha=.89$ non clinical sample. Reliability coefficient on current sample was also found out. The computed alpha coefficient for total sample was .94 with mean standard deviation $(M=36.61, S D=22.34)$. Its computed value for smokers.93 with $(M=26.52, S D=18.86)$, Cannabis user .92 with $(M=31.46, S D=19.80)$, and heroin addicts $\alpha=.93$ with $(M=50.76, S D=22.34)$.

Trait Anger Expression Scale (Rashid \& Siddiqui, 2005). It had 25 items four point likert scale (completely agree $=3$, somewhat agree $=2$, slightly agree $=1$ and completely disagree $=$ $0)$. It had four factors as items $(2,4,5,7,10,11)$ measure state anger, expressive anger $(8,14$, $15,17,18,25)$, anger in related items are $(3,16,19,24)$, and three item $(21,22,23)$ only related with anger out. A few items have reversed scoring (1, 6, 9, 12, 20) and their score solely add up in total score. The anger problem determined with total score, and Standard deviation $S D=13.82$ from mean score $M=38.82$ took as need for considerations. Kazmi (2008) established this scale reliability and validity against STAXI on university students. TAES reliability coefficient estimated .79 and found significant correlation with STAXI. The concurrent validity was above $(r=.50)$ that is significant. The correlation values for State anger is $(r=.41)$, Trait anger $(r=.5)$, Anger in $(r=.42)$, Anger Out $(r=.39)$, anger control $(r=-.53)$ and Anger Expression $(r=.63)$. Trait Anger Expression Scale computed alpha coefficient on total sample $(N=150)$ was .83, while on anger dimensions.70 for state anger, .72 for expressive anger, .60 anger in and .60 for anger out. Scale reliability on sample group also calculated that showed alpha value of TAES on smoker for was .86 and on state anger .70, expressive anger .72, anger in .70 and anger out .70. Cannabis users was .80, state anger .70, expressive anger .60, anger in .52 and anger out .51. Heroin addict group had .80, State anger .60, expressive anger .75, anger in .60 and anger out .54 .

Drug Related Locus of Control Scale (Hall, 2001). Quadsia \& Kausar (2013) translated version of Drug related locus of control scale (Elizabeth, 2001) was used in data collection for assessing internal and external locus of control. This scale was 15 item forced choice questionnaires. Each item had two options "a" and "b" participant had to select one option between two. Some items had reversed scoring $(1,3,5,8,11,14,15)$, these items must be reversed scored in following order $(1=2)$ and $(2=1)$. 
Hall (2001) the scale had good psychometric properties, this scale alpha coefficient was calculated .81 and split half reliability was .76. This scale convergent validity established with addiction severity index that was significantly correlate $(r=.301, p<.00)$. Drug Related Locus of Control Scale translation reliability coefficient also computed on current sample to see its consistency of scores. Computed alpha coefficient on total sample was .60 and it was also estimated on sample groups as alpha value on smokers group was .60, Cannabis User group .60 and heroin addicts group .60 .

\section{RESULTS}

Initially descriptive and frequency distribution of demographic variables were found out. Then correlation analysis was carried on anger, depression and DRLOC on total sample and sample group. Group difference in anger and depression were explored with MANOVA and predictors determined with regression analysis

Table 3.1, Inter Correlation of all Measures and their Subscales on Total Sample $(N=150)$ and heavy Smokers $(n=50)$

\begin{tabular}{|c|c|c|c|c|c|c|c|c|c|}
\hline Variables & 1 & 2 & 3 & 4 & 5 & 6 & 7 & $M$ & $\overline{S D}$ \\
\hline TAES & - & $.83 * * *$ & $.87 * * *$ & $.67 * * *$ & $.62 * * *$ & $.48^{* * *}$ & .104 & 43.46 & 12.59 \\
\hline SA & $.87 * *$ & - & $.70 * * *$ & $.46^{* * *}$ & $.46^{* * *}$ & $.43^{* * *}$ & .11 & 10.35 & 4.38 \\
\hline EA & $.87 * * *$ & $72 * * *$ & - & $.52 * * *$ & $45 * * *$ & $.55 * * *$ & .15 & 8.61 & 4.98 \\
\hline $\mathrm{AI}$ & $.72 * * *$ & $.54 * * *$ & $.59 * * *$ & - & $.29 * * *$ & $.38 * *$ & .07 & 6.11 & 3.35 \\
\hline $\mathrm{AO}$ & $82 * * *$ & $.68 * * *$ & $.68 * * *$ & .52 & - & $.20^{*}$ & .08 & 4.89 & 2.31 \\
\hline SSDS & $.46 * *$ & $.39 * *$ & $.49 * * *$ & $.41 * *$ & $31^{*}$ & - & $.25 * *$ & 36.61 & 22.34 \\
\hline DRLOC & $.36 * *$ & $.31^{*}$ & $.41^{* *}$ & $.28^{*}$ & $.28 *$ & $.36 * *$ & - & 21.28 & 2.81 \\
\hline$M$ & 39.92 & 9.36 & 6.74 & 5.68 & 4.53 & 26.52 & 21.64 & & \\
\hline$S D$ & 13.86 & 4.09 & 4.82 & 3.44 & 2.52 & 18.86 & 2.81 & & \\
\hline
\end{tabular}

Note. TAES = Trait Anger Expression Scale, $\mathrm{ST}=$ state anger, EA = Expressive Anger, $\mathrm{AI}=$ anger in, $\mathrm{AO}=$ anger out, SSDS $=$ Siddiqui Shah Depression Scale, DRLOC $=$ Drug Related Locus of Control. ${ }^{*} p<.05 .{ }^{* *} p<.01 . * * * p<.001$

The Table 3.1 indicates inter correlation of all scales on total sample and heavy smokers group. It demonstrates anger highly significantly correlate with depression. it indicates that anger is significantly correlated with depression as rise in anger resulted in rise in depression. Anger dimensions state anger and trait anger have strong positive relationship with depression. Anger in and anger out has less significant relationship with depression. DRLOC is only positively correlated $(r=.25, p<.05)$ with depression. There is no statistically significant correlation found between anger and Drug Related Locus of Control. While in heavy smokers' group anger, depression and locus of control have significant positive relationship. Expressive anger dimension is significantly correlated with depression and significant relationship observed with DRLOC. That shows high expressive anger associate with high depression and external drug locus of control. Anger out dimension has comparatively least significant relationship with 
depression and DRLOC. Depression and DRLOC also have strong relationship with depression in smokers group.

Table 3.2, Inter Correlation of all measures on Cannabis Users and Heroin Addicts $(n=50)$

\begin{tabular}{|c|c|c|c|c|c|c|c|c|c|}
\hline Variables & 1 & 2 & 3 & 4 & 5 & 6 & 7 & $M$ & SD \\
\hline TAES & - & $.80 * * *$ & $.88 * * *$ & $.70 * * *$ & $.50 * * *$ & $.64^{* * *}$ & .006 & 43.98 & 11.85 \\
\hline SA & $.80 * * *$ & - & $.68 * * *$ & $.39 * *$ & $.36^{*}$ & $.56 * * *$ & .11 & 10.18 & 4.35 \\
\hline EA & $.85 * * *$ & $.65 * * *$ & - & $.56^{* * *}$ & $.30 *$ & $.62 * * *$ & .12 & 8.84 & 4.39 \\
\hline $\mathrm{AI}$ & $.55 * * *$ & $.39 * * *$ & $.44 * * *$ & - & .24 & $.42 * *$ & -.00 & 5.42 & 3.15 \\
\hline $\mathrm{AO}$ & $.48 * * *$ & $.32 * * *$ & $.33 * * *$ & .11 & - & $.31 *$ & -.03 & 5.38 & 2.52 \\
\hline SSDS & .24 & .17 & $.34 * * *$ & .15 & .01 & - & .15 & 31.46 & 19.80 \\
\hline DRLOC & -.14 & -.12 & -.04 & -.16 & -.00 & .26 & - & 26.54 & 2.68 \\
\hline$M$ & 47.42 & 11.94 & 10.94 & 7.22 & 4.90 & 50.76 & 21.66 & & \\
\hline$S D$ & 11.59 & 3.71 & 4.62 & 3.16 & 2.46 & 21.03 & 2.86 & & \\
\hline
\end{tabular}

Note. TAES = Trait Anger Expression Scale, $\mathrm{ST}=$ stat anger, EA = Expressive Anger, AI = anger in, $\mathrm{AO}=$ anger out, SSDS $=$ Siddiqui Shah Depression Scale, DRLOC $=$ Drug Related Locus of Control. ${ }^{*} p<.05 .{ }^{* *} p<.01 .{ }^{* * *} p<.00$

The Table 3.2 shows inter correlation of anger, depression and locus of control in cannabis users and heroin addicts. It depicts Anger is very significantly correlated with depression in cannabis users and there is no statistical significant relationship observed between anger and DRLOC. State anger and Trait anger have strong positive relationship with depression. Anger in relationship with depression is also significant and less significant on anger out. Among Heroin addicts only expressive anger dimension highly significantly correlated with depression. There is no statistical significant relationship observed between anger depression and DRLOC in heroin addicts. Anger dimensions are significantly correlated $(p<.001)$ with each other but do not have significant relationship with depression and drug related locus of control. Neither statistical significant association Observe between anger and Locus of Control. 
Table 3.3, Multivariate Analysis of Variance for Demographic Variables with Trait Anger Expression Scale, Siddiqui Shah Depression Inventory and Drug Related Locus of Control.

\begin{tabular}{|l|l|l|l|l|l|l|}
\hline Source & $\begin{array}{l}\text { Dependent } \\
\text { Variables }\end{array}$ & SS & Df & MS & F & P \\
\hline Sample Categories & TAES & 1610.45 & 2 & 805.22 & $5.18^{* *}$ & .007 \\
& State Anger & 120.280 & 2 & 60.14 & $3.61^{*}$ & .029 \\
& Expressive Anger & 441.00 & 2 & 220.50 & $10.52^{* * *}$ & .000 \\
& Anger In & 90.65 & 2 & 45.32 & $4.34 *$ & .01 \\
& Anger Out & 26.01 & 2 & 13.00 & 1.87 & .15 \\
& SSDS & 16582.49 & 2 & 8291.2 & $20.86^{* * *}$ & .000 \\
& DRLOC & 42.65 & 2 & 21.32 & 2.73 & .06 \\
\hline Error & 22827.34 & 147 & 155.28 & & & \\
& 2445.06 & 147 & 16.63 & & & \\
& 3081.16 & 147 & 20.96 & & & \\
& 1531.940 & 147 & 10.42 & & & \\
& 1022.28 & 147 & 6.95 & & & \\
& 58404.18 & 147 & 397.30 & & & \\
& 1148.44 & 147 & 7.81 & & & \\
\hline
\end{tabular}

Note. TAES = Trait Anger Expression Scale, SSDS = Siddiqui Shah Depression Scale, DRLOC= Drug Related Locus of Control Scale. Only significant results have been reported. ${ }^{*} p<.05$, ${ }^{* *} p<$ $.01, * * p<.001$

Table 3.3 Multivariate analysis of variance shows TAES significantly differentiated $(F=5.18, p$ $<$.01) in sample categories. In Anger dimensions, significant difference seen on expressive anger dimension $(F=10.52, p<.001)$. State anger less significantly different among sample groups $(F$ $=3.61, p<.03)$ as compare to expressive anger. The difference is also observed in anger in but anger out is not statistically significant among three groups. While, the significant difference $(F$ $=20.86, p<.001$ ) noted on SSDS among sample categories. It indicates level of depression significantly differentiated among groups.

Post Hoc analysis carried out to see mean difference among sample categories on dependent variables. The analysis shows on TAES heroin addicts significantly differentiate $(p<.001)$ to smoker and cannabis users. Smokers and cannabis do not differ in their anger level with each others. Heroin addict has also high level of state anger $(p<.05)$ then smokers. Expressive anger significantly discriminates among three groups. As heroin addicts have highest level of expressive anger than cannabis users and heavy smokers. Expressive anger difference is significant $(p<.05)$ between heroin addicts and cannabis users. Cannabis users and heavy smokers difference is also significant $(p<.05)$ to each other on expressive anger, it illustrates cannabis users have more expressive anger then heavy smokers. SSDS score differentiated among sample categories as well. Heroin addict have very significantly high $(p<.001)$ level of depression then cannabis users and heavy smokers. There is no statistical significant difference 
observed in depression level between heavy smokers and cannabis users. Drug related locus of control difference shows between heroin addict and cannabis users $(p<.05)$. DRLOC difference present between cannabis users and smokers $(p<.05)$. Heroin addicts and heavy smokers do not have difference in DRLOC. It suggests cannabis user have high level of DRLOC as compare to smoker and cannabis users.

Table 3.4, Stepwise Regression Analysis to Identify Main Predictors of Depression on Total sample

\begin{tabular}{|l|l|l|l|l|l|l|l|}
\hline \multicolumn{9}{|c|}{ Depression } \\
\hline & Model 1 & Model 2 & Model 3 & Model 4 & Model 5 & \multicolumn{2}{|l|}{} \\
\hline Variables & $\mathrm{B}$ & $\mathrm{B}$ & $\mathrm{B}$ & $\mathrm{B}$ & $\mathrm{B}$ & $95 \%$ CI \\
\hline Constant & $3.25^{* * *}$ & $3.96^{* * *}$ & 11.61 & 11.95 & -20.90 & 7.68 & 20.57 \\
\hline EA & $.32^{* * *}$ & $.32^{* * *}$ & $.32^{* * *}$ & $.33^{* * *}$ & $.39^{* * *}$ & 1.87 & 3.16 \\
\hline QDI & & $.13^{* *}$ & $.136^{* *}$ & $-.26^{* *}$ & $-.26^{* *}$ & -.66 & -.14 \\
\hline DRLOC & & & $.54^{* *}$ & $.16^{*}$ & $.16^{*}$ & .45 & 2.59 \\
\hline QS & & & & $.18^{*}$ & $.17^{*}$ & .09 & .82 \\
\hline Occupation & & & & $.17^{*}$ & $.14^{*}$ & .18 & 6.18 \\
\hline $\mathrm{R}^{2}$ & .30 & .33 & .37 & .40 & .42 & & \\
\hline $\mathrm{F}$ & $59.70^{* * *}$ & $35.10^{* * *}$ & $27.24^{* * *}$ & $22.76^{* * *}$ & $19.55^{* * *}$ & & \\
\hline$\Delta \mathrm{R}^{2}$ & & .03 & .03 & .02 & .01 & & \\
\hline$\Delta \mathrm{F}$ & 59.70 & 7.63 & 7.96 & 6.20 & 4.40 & & \\
\hline
\end{tabular}

Note. EA = expressive anger, QDI= quantity of drug intake, DRLOC = Drug Related Locus of Control Scale, QS= quantity of smoking. Control Variables Included age, education, income, duration of drug use, duration of smoking, state anger, anger in, anger out. ${ }^{*} p<.05$, ${ }^{* *} p<.01$, ${ }^{* *} p<.001$

The Table 3.4 of stepwise regression analysis identifies five predictors of depression in total sample. Step one suggested expressive anger as positive strongest predictor of depression $(\beta$ $=.55, t=7.72, p=<.001)$. Standard beta value predicts expressive anger relatively strongest predictor. That produce equation model fit $\left(R^{2}=.30, F=59.70, p=.001\right)$ when regressed against scores of depression with $30 \%$ variance. Step two retain quantity of drug as negative predictor $(\beta$ $=-.19, t=-2.76, p=<.01)$. Step three suggested DRLOC positive predictor of depression with equation fit model $\left(R^{2}=.37, F=27.24, p=.01\right)$ that revealed DRLOC predicts with variance level of .37\%. Fourth step includes quantity of smoking as combine predictor $(\beta=18, t=-2.49$, $p=<.05)$ with strong model fit $\left(R^{2}=.40, F=22.76, p=.001\right)$ and explains variance level $40 \%$. Step five only suggested occupation as positive predictor $(\beta=14, t=-2.09, p=<.05)$ explaining variance $.42 \%$ and significant model $\left(R^{2}=.42, F=19.55, p=.001\right)$. 
Table 3.5, stepwise Regression Analysis to explore Depression Predictor in Heroin Addicts, Cannabis Users and Heavy Smokers

\begin{tabular}{|c|c|c|c|c|}
\hline \multirow[b]{3}{*}{ Predictors } & \multicolumn{3}{|c|}{ Heroin Addicts } & \\
\hline & \multicolumn{2}{|c|}{ Model 1} & Model 2 & \\
\hline & $B$ & \multicolumn{2}{|c|}{$B$} & $95 \% \mathrm{CI}$ \\
\hline Constant & \multicolumn{2}{|c|}{$33.56 * * *$} & & $(18.73,48.38)$ \\
\hline Expressive Anger & \multicolumn{2}{|c|}{$.35 *$} & & $(.34,2.84)$ \\
\hline DRLOC & \multicolumn{3}{|c|}{$.27^{*}$} & $(.058,3.95)$ \\
\hline $\mathrm{R}^{2}$ & \multicolumn{2}{|l|}{.12} & .19 & \\
\hline $\mathrm{F}$ & \multicolumn{2}{|l|}{$6.54 *$} & $5.64^{* *}$ & \\
\hline$\Delta \mathrm{R}^{2}$ & \multicolumn{3}{|c|}{$.07 *$} & \\
\hline$\Delta \mathrm{F}$ & \multicolumn{3}{|c|}{4.29} & \\
\hline \multirow[b]{2}{*}{ Predictors } & \multicolumn{2}{|c|}{ Cannabis Users } & \multicolumn{2}{|c|}{ Heavy Smokers } \\
\hline & Model $1 B$ & $95 \%$ CI & Model $1 B$ & $95 \%$ CI \\
\hline Constant & 8.00 & $(-2.58,18.60)$ & $13.14 * *$ & $(4.88,21.41)$ \\
\hline Expressive Anger & $.60 * * *$ & $(1.47,3.67)$ & $.49 * * *$ & $(.97,2.99)$ \\
\hline $\mathrm{R}^{2}$ & .36 & & .24 & \\
\hline $\mathrm{F}$ & $22.40 * * *$ & & $15.63 * * *$ & \\
\hline$\Delta \mathrm{R}^{2}$ & $.36 * * *$ & & $.24 * * *$ & \\
\hline$\Delta \mathrm{F}$ & 22.40 & & 15.63 & \\
\hline
\end{tabular}

Note. $\mathrm{CI}=$ confidence interval, $\mathrm{EA}=$ expressive anger, $\mathrm{QDI}=$ quantity of drug intake, $\mathrm{DRLOC}=$ Drug Related Locus of Control Scale, QS= quantity of smoking. Control variables included age, education, income, duration of drug use, duration of smoking, state anger, anger in, anger out. ${ }^{*} p$ $<.05, * * p<.01, * * p<.00$

Table 3.5. Step wise regression analysis suggested expressive anger and Locus of control as positive predictor of depression in Heroin addicts. Model one suggested expressive anger as main positive predictor with $12 \%$ of variance $\left(R^{2}=12, B=.35 p<.05\right)$. Thus at step two it combine expressive anger and Drug related Locus of control as another predictor of depression with variance of $19 \%\left(R^{2}=19, B=.27, p<.05\right)$.

Expressive anger is also main predictor of depression among cannabis users and smokers. Step wise regression analysis suggested Expressive anger as positive predictor of depression with the Variance level of $36 \%$. $\left(R^{2}=36, B=.60, p<.001\right)$. Other variables have been excluded in analysis due to non significance values. Expressive anger also main predictor of depression in smokers as well.

\section{DISCUSSION}

The results show anger and depression have strong relationship among smokers, cannabis users and heroin addicts. The Similar relationship of anger and depression suggested in previous studies in clinical population (Brody, Haa ga, Kirk, \& Solomon, 1999) and other studies demonstrated that association in normal population (Deffenbacher, et al., 1996; Robbins \& 
Tanck, 1997). Anger and depression are also as risk factor for drug abuse and vice versa. Some studies reported that depressed people use drugs and other studies viewed that elevated anger and depression leads drug use. Zawawi and Hamaideh, (2009) found significant relationship in depressive symptoms, drug use and life dissatisfaction among college students. There are scarce studies showing relation of anger depression and locus of control among drug addicts and smokers.

Anger, depression and drug related locus of control only interrelated in smokers group. Previous studies had been seen heavy smoking in relation with anger provocation (Gehricke, et al. 2009), Kalma and Smith (2005) associated nicotine with tension and jittering. The relationship of Heavy smoking and depression is well established (Breslau, Novak, \& Kessler, 2004). Heavy smoking has been studied with Schizophrenia and other mental illness besides depression (Wehring, et al. 2012). Various studies have been revealed smokers nicotine dependence and vulnerability for misuse of other drugs in boys and girls (Biedeman, Petty, Hammenes, Batchelder, \& Faraone, 2012). Grant et al. (2004) as cited by Weinberger, Sacco, \& Georg, (2006) reported high prevalence rate of anger, depression, drug dependence, schizophrenia and other mental health problem in smokers. Cigarette smoking relationship with schizophrenia, depression, anxiety and personality disorders is not yet fully differentiated. Further physiological and psychological researches are needed to study association of disorder type and enduring effect of smoking.

Anger and depression relationship among cannabis group also distinctive but it has no association with drug related locus of control. This is only consistent with few previous studies as DePino (2008) was seen no relevance of locus of control with rewards sensitivity and outcomes expectancy. There is no further literature available that define locus of control and depression relationship particularly in cannabis users. Whereas State anger, Expressive anger are found highly related with depression. Anger out is less likely to correlate with state, expressive, anger in and depression in cannabis users. Sung, Erkanli, Angold, and Costello (2004) were correlated cannabis use with mental disorders and more specifically major depression. As many studies found strong association between externalized disorders in cannabis users. Some other sssfinding suggested association between cannabis use and psychosis (Arseneault, Cannon, \& Poulton, 2002). However, some studies link cannabis with positive mood alteration effects that help them to change their negative mood (Boys \& Marsden, 2003; Simons Gaher, Correia, Hansen, \& Christopher, 2005). Among Heroin addicts, only expressive anger dimension is strongly related with depression. Depression is pertinent among heroin addicts. A number of studies illustrated this relation, Maremmani, Pacini, Pani, Perugi, Deltio, \& Deltito, (2007) suggested depression co morbidity in heroin addicts. Drug related locus of control is not related with depression and anger.

Multivariate analysis of variance shows significant difference in anger, depression and drug related locus of control among smoker, cannabis users and heroin addicts. Heroin addicts 
exclusively high anger and depression than cannabis users and smokers. Cannabis and smoker only differ on expressive anger and depression. Heroin Addicts have distinctively high level of expressive anger, state anger and very high level of depression than smokers and cannabis users. De Moja (1997) found similar finding in opiate addicts that they had high level of state, trait and expressive anger and less control on anger feeling. Carmelo and De Moja (1997) explored in different series of studies that drug addicts have external locus of control and they have less control on their anger feelings. Though locus of control difference was not seen in this study yet this study confirmed opiate addict extreme anger states. Heroin addicts' higher trait, state anger and depression difference with normal people is evidence based. But its comparison with cannabis and smoker in researches are yet not fully explored.

Post Hoc analysis shows significant difference between smoker and cannabis on expressive anger domain and DRLOC. There is no significant difference seen on overall depression and anger level between smokers and cannabis users. Cannabis users have slightly high level of DRLOC that indicates their more external locus of control than smoker and heroin addicts. Limited literature is available which explained anger and depression difference between smokers and cannabis users. Some studies suggested cannabis users have more anger than non-users (Stoner, 1988). Whereas about cannabis use and level of anger concern studies shows contradictory results. Some studies viewed cannabis users have no difference in anger and violence or have negative association with aggression. White and Stephen (1998) marijuana has negative effect on aggression during early age periods 12-18 to 15-21. But other suggested and explained higher level and positive association of violence in cannabis withdrawal. However it has confirmed that cannabis user and smokers are more prone to depression as compare to nonsmokers.

Overall regression analysis predicts expressive anger as main predictor of depression on total sample analysis. Along with some other predictors like as quantity of drug intake, Drug related locus of control and quantity of smoking. Daniel, Goldston, Erkanli, Franklin, and Mayfield (2009) showed high trait anger and outward expression of anger which positively predicts suicide attempt and major depression episode among young adults. Trait anger is often taken as high risk factor for depression and stress in general population, and also in clinical population (Mook, et al. 1990). Such finding supports our current result as it predicts expressive anger as contributing factor for depression. Quantity of drug intake and quantity of smoking both predicts depression in total sample. Depression increased with quantity of drug intake and smoking. Smoking effects cannot be eliminated in heroin and cannabis group because it is hard to find people who only use cannabis or heroin but did not smoke cigarette. Therefore smoking effects observed in total sample relates to extent smoking. NIDA (2000) reports major depression episode is common among nicotine dependent daily smokers. In current sample almost $80 \%$ participants smoke more than 10 cigarettes. 
As results explore, DRLOC positively predicts depression in total sample. That indicates external sense of drug related locus of control predict depression. These finding are strongly supported with previous studies. Many studies consistently explored that higher level of depression is associated with more external Locus of control (Benson \& Deeter, 1992; Hooke \& Page, 2002). Regression analysis on heroin addict group illustrates, expressive anger and DRLOC predicts depression. Expressive anger is also identified as predictor of depression among cannabis users and smokers. Heroin addicts are exclusive group with high level of anger expression and depression. Therefore expressive anger is considers being strongest predictor of depression in heroin addicts than cannabis users and smokers group. Trait and expressive anger role in development of depression is well documented (Balsamo, 2012; Riley et al.1989). Expressive anger also predictor of external drug related locus of control in heroin addicts. External locus of control is also related to positive associated with depression (Macleod \& Macleod, 1998; Robinson \& Kelley, 1998).

\section{CONCLUSION}

On the basis of current results, it can be concluded that expressive anger and depression have strong relationship in heavy smokers, cannabis users and heroin addict. As they more experience anger they will more experience depression. In heroin addicts, Expressive anger only positively related with depression. This relationship is stronger in cannabis users with other domain of anger like State anger, Expressive anger, anger in and anger out which were positively related with depression. That gives view anger states were more enduring among cannabis users. this manifestation was similar among heavy smokers but Drug related locus of control is also associated with anger and depression in heavy smokers. It completes model of previous studies that people experience more anger have more external locus of control and depression. DRLOC has no association with anger and depression among heroin addicts and cannabis users

Heroin addicts have exclusively high level of state, expressive and anger in feeling and depression than cannabis users and heavy smokers. Cannabis users and smokers have considerable difference on state anger, anger in and anger out. Cannabis users are second in level of depression and heavy smokers are lest in depression. No difference was found on quantity of drug intake and level of anger and depression. Thus, there was no significant relationship and differences seen in demographic variables (age, marital status, family system, duration of drug use etc.) on level of anger and depression

Expressive anger has identified as leading factor of depression in smokers, cannabis users and heroin addicts. Quantity of drug intake and quantity of cigarette were other predictors of depression with DRLOC in total sample analysis. Similar expressive anger also predicts depression in cannabis users Smokers. It can be assumed that expressive anger would be a risk factor of drug abuse and smoking that increase chances of depression. External Drug related locus has only been determined as predictor of depression in heroin addicts. No difference was found on quantity of drug intake and level of anger and depression. 


\section{REFERENCES}

Ahmad, B., \& Mufti, K. A. (1998). Prevalence of depressive disorder in heroin dependents. Journal of Postgraduate Medical Institutes, 14(2), 68-70.Retrieve from http:// www. jpmi.org.pk/index.php/jpmi/article/view/704

Al Absi, M., Carr, S. B., \& Bongard, S. (2007). Anger and Psychobiological Changes During Smoking Abstinence and in Response to Acute Stress: Prediction of Smoking Relapse. International Journal of Psychophysiology, 66 (2), 109-115. Retrieved from http://www.ncbi.nlm.nih.gov/pmc/articles/PMC2443944

Arendt, et al. (2007). Testing the self-medication of depression and aggression in Cannabis dependent subjects. Abstract for poster sessions / European Psychiatry, 22, 101-220.

American Psychiatric Association. (1994). Diagnostic and Statistical Manual of Mental Disorders (4th ed.). Washington, DC: Author.

American Psychological Association (2009). Publication manual of the American Psychological Association (6th ed.). Washington Dc: Author. Abdolmanafi, A., Besharat, M. A., Farahani, H., \& Khodaii, M. R. (2011). The moderating role of locus of control on the relationship between anger and depression in patients with major depression disorder. Social and Behavioral Sciences, 30, 297- 301. doi:10.1016/j.sbspro.2011.10.059

Breslau, N., Novak, S. P., \& Kessler, R. C. (2004). Psychiatric disorders and stages of smoking. Biological Psychiatry, 55(1), 69-76.doi: 10.1016/S0006-3223(03) 00317-2

Biedeman, J., Petty, C. R., Hammerness, P., Batchelder, H., \& Faraone, S.V. (2012). Cigarette smoking as risk factor for other substance misuse: 10 years study of individuals with attention deficit hyperactivity disorder. British Journal of Psychiatry.201 (3), 207-214. doi: 10.1192/bjp.bp.111.100339

Benassi, V. A., Sweeney, P. D., \& Dufour, C. L. (1988). Is there a relation between locus of control orientation and depression. Journal of Abnormal Psychology,97(3), 357- 367. doi:10.1037/0021-843X.97.3.357

Benson, L. T., \& Deeter, T. E. (1992). Moderators of the relation between stress and depression in adolescents. School Counselor, 39, 189-194.

Bergen, W. A., \& Caporaso, N. (1999). Review: Cigarette smoking. Journal of National Cancer Institute, 91(16), 1365-1375. Retrieved from http://jnci.oxfordjournals .org/

Balsamo, M. (2012). Personality and depression: evidence of a possible mediating role for anger trait in the relationship between cooperativeness and depression. Comprehensive Psychiatry. doi:10.1016/j.comppsych.2012.05.007

Bridewell, W. B., \& Chang, E. C. (1998). Distinguishing between anxiety, depression, and hostility: relations to anger-in, anger-out, and anger control. Personality Individual Differences. 22(4), 587-590. doi:http://dx.doi.org/10.1016/S0191-8869(96)00224-3

Brody, C. L., Haaga, D. A. F., Kirk, L., \& Solomon, A. (1999) Experiences of anger in people who have recovered from depression and never-depressed people. The Journal of Nervous and Mental Disease, 187, 400-405. Retrieved from http:// www.ncbi.nlm.nih.gov/pubmed/10426459 
Boys, A., \& Marsden, J. (2003). Perceived functions predict intensity of use and problems in poly substance users. Addiction, 98, 951-963.

Carmelo, A., De Moja, C. A., \& Speilberger, C. D. (1997). Anger and drug addiction. Psychological Report.81, 152-154. doi: 10.2466/pr0.1997.81.1.152

Deniel, S.S., Goldston, D. B., Erkanli, A., Franklin, J. C., \& Mayfield, A. M. (2009). Trait anger, anger expression, and suicide attempts among adolescents and young adults: A prospective study. Journal of Clinical Child and Adolescent Psychology, 38(5), 661-671. doi:10.1080/15374410903103494

Deffenbacher, J. L., et al. (1996) State-trait anger theory and the utility of the Trait Anger Scale. Journal of Counseling Psychology, 43, 131-148.

Depino, V. M. (2008). Reward Sensitivity and outcomes expectancies predict both alcohol and cannabis use in young adults. (Doctoral dissertation, RMIT University). Retrieved from http://researchbank.rmit.edu.au/eserv/rmit:9517/ De_Pino.pdf

Degenhardt, L., Hall, W., \& Lynskey, M. (2001). The relationship between cannabis use, depression and anxiety Australian adults: findings from the National Survey of Mental Health and Well-Being. Psychiatry Epidemiology, 36, 219-227. doi: http://dx.doi.org/10. 1017/S0033291701003865

Farbstein, J. A. (2011). Running head: Locus of Control, Personality and Parenting. (Master's thesis, Mount Saint Vincent University). Retrieved from http://dc.msvu.ca:8080/fr/bitstream/handle/10587/1143/JillyanFarbsteinMASPThesis201 1.pdf?sequence $=1$

Gehricke, J., et al. (2009). Nicotine-induced brain metabolism associated with anger provocation. Behavioral and Brain Function, 5(19), 1-6. doi: 10.1186/1744-9081-5-19.

Hall, A. E. (2001). Feeling about drug use: drug related locus of control scale. Integrated Substance Abuse Program. University of California. Retrieved from http:// www.uclaisap.org/cjs/assets/docs/DRLOC_scale_instrumentation.pdf

Hughes, J. R., Hatsukami, D. K., Mitchell, J. E., \& Dahlgen, L.A. (1986). Prevalence of smoking among psychiatric outpatients. American Journal of Psychiatry, 143,993-997. Retrieved from http://legacy.library.ucsf.edu/documentStore/m/p/l/mpl28a99/Smpl28a99.pdf

Hooke, G. R., \& Page, A. C. (2002). Predicting outcomes of group cognitive behavioral therapy for patients with affective and neurotic disorders. Behavioral Modification, 26, 648-658.

Iliceto, P., et al., (2011). Relationship between Temperament, Depression, Anxiety, and Hopelessness in Adolescents: A Structural Equation Model. Depression Research and Treatment.doi:10.1155/2011/160175

Kazmi, U. R. (2008). A validity Study of Trait Anger and Expression Scale (TAES) Against State Trait Anger Expression Inventory (STAXI) (MS Unpublished Thesis).GC University Lahore.

Killen, J. D., Fortmann, S. P., Telch, M. J., \& Newman, B. (1988). From Light Smokers? A comparison after 48 hours without cigarettes, 260(11), 15811585.doi:10.1001/jama.1988.03410110089033. 
Malik, S. (2009). Personality trait as a risk factor of smoking. (Unpublished Thesis of Master class). University of Punjab, Lahore.

Maremmani, I., Pacini, M., Pani, P. P., Perugi, G., Deltito, J., \& Akiskal, H. (2007): The mental status of 1090 heroin addicts at entry into treatment: should depression be considered a ‘dual diagnosis’? Annals of General Psychiatry, 6(31).doi: 10.1186 /17 44-859X -6-31

Macleod, L., \& Macleod, G. (1998). Control cognitions and psychological disturbance in people with contrasting physically disabling conditions. Disability Rehabilitation, 20(12), 448456. Retrieved from http://www.ncbi.nlm.nih.gov/pubmed/9883394

Nazar, F. (2008). Stress and anger among smokers and non-smokers. (Unpublished master's thesis). Punjab University, Lahore.

Nashee, Q., \& Kausar, R. (2012). Urdu translation of Drug Related Locus of Control Scale. Lahore: (Unpublished M.Phil. thesis).Institute of Applied Psychology, University of the Punjab.

Niazi, R. S., Pervaiz, R., Minhas, F. A., \& Najam, N. (2005). Locus of Control and personality traits of male substance abusers and non-abusers. Journal of Pakistan Psychiatric Society,2 (1), 41-44. Retrieved from http://www.jpps.com .pk/ display_articles.asp?d=49\&p=art org.pk /full article_text.php?article_id $=2123$

Rao, S. R., Broom, K. M., \& Simpson, D. D. (2004). Depression and hostility as predictors of long-term outcomes among opiate users. Addiction . 99(5), 579-589. doi: 10.1111/j.13600443.2004.00686.x

Rashid, S., \& Siddiqui, S. (2005). Trait Anger and Expression Scale. Paper Presentation at International Psychiatric Conference . Karachi, Sindh. Pakistan.

Rotter, J. B. (1975). Some problems and misconception related to the construct of internal versus external control of reinforcement. Journal of Consulting and Clinical Psychology, 43, 5657.

Riley, W. T., Treiber, F. A., \& Woods, M. G. (1989). Anger and Hostility in Depression. Journal of Nervous \& Mental Disease, 177(11). Retrieved from http://journals.lww.com/jonmd/abstract/1989/11000/anger_and_hostility_in_depression.2 .aspx

Robbins, P. R., \& Tanck, R. H. (1997) Anger and depressed affect: interindividual and intra individual perspectives. Journal of Psychology, 131, 489-500.

Robinson, B. E., \& Kelley, L. (1998). Adult Children of Workaholics: Self-Concept, Anxiety, Depression, and Locus of Control. American Journal of Family Therapy, 26(3), 223-238. Retrieved from http://eric.ed.gov/?id=EJ585340

Sung, M., Erkanli, A., Angold, A., \& Costello, E.J., (2004). Effects of age at first substance use and psychiatric comorbidity on the development of substance use disorders. Drug Alcohol Depend, 75, 287-299.Reterived from http://www. sciencedirect.com/science/article/pii/S0376871604000936

Stoner, S. B. (1988). Undergraduate marijuana use and anger. The Journal of Psychology, 122(4), 343-347.doi:10.1080/00223980.1988.9915521 
Simons, J.S., Gaher, R.M., Correia, C.J., Hansen, C.L., \& Christopher, M.S. (2005). An affective-motivational model of marijuana and alcohol problems among college students. Psychology of Addictive Behaviors, 19, 326-334.

Sordo, L., et al. (2012).Depression among regular heroin users: The influence of gender. Addictive behavior, 32, 148-152. doi:10.1016/j.addbeh.2011.09.009

Siddiqui, S., \& Shah, A. A. (1992). The Assessment of Attributional Style of Depression and Non-Depressive through an Indigenously Developed Depression Scale. Doctoral dissertation, National Institute of Psychology, Islamabad.

Tafrate, R. C., Kassinove, H., \& Dundin, L. (2002). Anger Episode in High and Low Trait Anger Community Adults. Journal of Clinical Psychology, 58(12), 1573-1590. doi: 10.1002/jclp.10076

Tobacco Addiction (1998). National Institutes of Drug Abuse. Retrieved from http://www.drug abuse.gov/publications/research-reports/tobacco-addiction.

U.S. Department of Health and Human Services. Center for Behavioral health and Quality. (2006). National Survey on Drug Use and Health: National Findings. Retrieved from http://www.samhsa.gov/data/nsduh/2k6nsduh/2k6results.pdf

Wehring, et al. (2012). Clinical Characteristics of heavy and Non-heavy Smokers with Schizophrenia. Schizophrenia Research, 138, 285-289. doi:10.1016/j.schres.2012. 03.024.

Weinberger, A. H., Sacco, K. A., \& George, T. P. (2006). Comorbid tobacco dependence and psychiatric disorders. Psychiatric Times, 35-41. Retrieved from http://www.psychiatrictimes.com/articles/comorbid-tobacco-dependence-and-psychiatricdisorders

Zawawi, J. A., \& Hamaideh, H. S. (2009). Depressive Symptoms and Their Correlates with Locus of Control and Satisfaction with Life among Jordanian College Students. Europe's journal of Psychology, 5 (4). Retrieved from http://ejop. psychopen.eu/article/view/241

\section{Ethical Consideration}

Ethical Committee of Clinical Psychology Unit GC University Lahore approved this study. In which it was assured that this study procedure and method would not violate any ethical issues and basic ethical guide line must be followed. Initially institutional and organization permission were obtained from where and with the help of, data were collected. Participant consent form was necessary gained before data collection. During this study, we have also provided related services (counseling, education and guidance) to participant when it was required. 